\title{
Long Non-coding RNA in Neurons: New Players in Early Response to BDNF Stimulation
}

\author{
Vincenza Aliperti and Aldo Donizetti* \\ Department of Biology, University of Naples Federico II, Naples, Italy
}

Brain-derived neurotrophic factor (BDNF) is a neurotrophin family member that is highly expressed and widely distributed in the brain. BDNF is critical for neural survival and plasticity both during development and in adulthood, and dysfunction in its signaling may contribute to a number of neurodegenerative disorders. Deep understanding of the BDNF-activated molecular cascade may thus help to find new biomarkers and therapeutic targets. One interesting direction is related to the early phase of BDNF-dependent gene expression regulation, which is responsible for the activation of selective gene programs that lead to stable functional and structural remodeling of neurons. Immediate-early coding genes activated by BDNF are under investigation, but the involvement of the non-coding RNAs is largely unexplored, especially the long noncoding RNAs (IncRNAs). IncRNAs are emerging as key regulators that can orchestrate different aspects of nervous system development, homeostasis, and plasticity, making them attractive candidate markers and therapeutic targets for brain diseases. We used

OPEN ACCESS

Edited by:

Guilherme Lucas,

University of São Paulo, Brazil

Reviewed by:

Hermona Soreq,

The Hebrew University of Jerusalem,

Israel

Mohammad Faghihi,

University of Miami, USA

*Correspondence:

Aldo Donizetti

aldo.donizetti@unina.it

Received: 18 January 2016 Accepted: 18 February 2016 Published: 02 March 2016

Citation:

Aliperti V and Donizetti A (2016) Long Non-coding RNA in Neurons: New Players in Early Response to BDNF

Stimulation

Front. Mol. Neurosci. 9:15. doi: 10.3389/fnmol.2016.00015 microarray technology to identify differentially expressed IncRNAs in the immediate response phase of BDNF stimulation in a neuronal cell model. Our observations on the putative functional role of IncRNAs provide clues to their involvement as master regulators of gene expression cascade triggered by BDNF.

Keywords: long non-coding RNA, BDNF, immediate-early genes, neuronal gene expression, brain diseases

\section{THE ESSENTIAL ROLE OF BDNF IN NEURON LIFE}

Brain-Derived Neurotrophic Factor (BDNF) has been shown to have a central function in both neuronal development and in the adult nervous system. Knockout mice for BDNF usually die soon after birth and suffer developmental defects in the brain and sensory nervous system (Ernfors et al., 1995). Suppression of BDNF expression results in defective long-term potentiation (LTP) and memory formation (Korte et al., 1995; Linnarsson et al., 1997; Ma et al., 1998; Mu et al., 1999). In contrast, treatment of hippocampal slices from BDNF knockout mice with recombinant BDNF completely reversed deficits in LTP and significantly improved deficits in basal synaptic transmission (Patterson et al., 1996). BDNF interaction with NTRK2 receptor activates three signaling pathways: PI3K-Akt (PI3K, phosphatidylinositol-3 kinase), Ras-MAPK (MAPK, mitogen-activated protein kinase), and PLC $\gamma-\mathrm{Ca}^{+}$(PLC, phospholipase C; Duman and Voleti, 2012). It is also known to regulate a large spectrum of processes of the nervous system, including cell survival, growth, and differentiation (Casaccia-Bonnefil et al., 1999; Bibel and Barde, 2000; Huang and Reichardt, 2003; Park and Poo, 2013; Suliman et al., 2013; Zagrebelsky and Korte, 2014), 
synaptic plasticity of neurons, and LTP (Xu et al., 2000; Bramham and Messaoudi, 2005; Gottmann et al., 2009; Minichiello, 2009; Mizui et al., 2014; Zagrebelsky and Korte, 2014; Leal et al., 2015). BDNF's roles in neuronal processes during development and adulthood, support its potential role in the pathogenesis and treatment of both neurological and psychiatric disorders (Pruunsild et al., 2007; Nagahara and Tuszynski, 2011; Weissmiller and $\mathrm{Wu}, 2012)$. In fact, BDNF exerts potent prosurvival and functional effects in models of neurological diseases such as Parkinson's (Howells et al., 2000; van der Kolk et al., 2015), Huntington's (Zuccato et al., 2008; Jiang et al., 2013), and Alzheimer's diseases (Holsinger et al., 2000; Michalski and Fahnestock, 2003; Peng et al., 2005; Faria et al., 2014), as well as depression and other psychiatric disorders (Karege et al., 2002; Aydemir et al., 2005; Gonul et al., 2005; Cunha et al., 2006).

\section{BDNF: THE MOLECULAR MECHANISM OF ACTION}

Understanding the molecular mechanisms of BDNF's functions may help to develop efficient therapeutic strategies for brain diseases. The molecular cascade triggered by BDNF has largely been investigated in the adult hippocampus, which retains a high degree of synaptic plasticity into adulthood. The effects of BDNF on LTP have been largely assigned to effects on modulation of receptor trafficking and local protein synthesis at the synapse by local activation of the translation machinery (Leal et al., 2014). BDNF acts at different levels to increase translation activity by altering the phosphorylation of proteins involved in the initiation step of protein synthesis, such as the guanine nucleotide exchange factor eIF2B (Takei et al., 2001) and eIF4E and 4EBP1 (Takei et al., 2004). In addition, BDNF can affect the elongation step, as shown in cultured cortical neurons, where BDNF stimulation was shown to increase the phosphorylation (activation) of eukaryotic elongation factor 1A (eEF1A; Inamura et al., 2005; Leal et al., 2014).

\section{BDNF AND DE NOVO GENE EXPRESSION}

Long-term effects of BDNF on synaptogenesis, synaptic plasticity, and cell survival often depend on de novo gene expression. BDNF first affects the expression of genes (immediate-early genes, IEGs) that are regulated directly downstream of its signal transduction pathways and couple early signals to late expression of the downstream target responsible for persistent changes in neuronal phenotype. Some BDNF-induced IEGs involved in synaptic plasticity have been identified. Among them, activityregulated cytoskeleton-associated protein $(A R C)$, salt-inducible kinase 1 (SIK1), and transcription factor NR4A1 (Nur77), have been shown to be up-regulated early by BDNF stimulation of neurons (Ying et al., 2002; Rao et al., 2006; Zheng et al., 2009; Finsterwald et al., 2013). Beyond the classical proteincoding IEGs, micro-RNAs (miRNAs) have also been singled out in the early response to BDNF stimulation. For example,
miR-132 has been shown to be markedly up-regulated early after BDNF treatment of cortical neurons and involved in neuron morphogenesis likely triggering a rapid and persistent downregulation of protein levels (Vo et al., 2005). Both the proteins and miRNA classes of regulators therefore seem to participate in the early response to BDNF stimulation to induce the expression of downstream effectors involved in long-term synaptic changes and cell survival. Mechanisms regulating the initial molecular cascade are likely even more intricate when considering that a new class of non-coding RNA has recently been emerging as a key regulator of gene expression: the long non-coding RNA (lncRNA).

\section{LONG NON-CODING RNA: A NEW CLASS OF REGULATORY RNA}

Long non-coding RNA are a heterogeneous class of numerous transcripts mainly produced by RNA polymerase II and defined as RNA molecules of more than 200 bases in length with no protein-coding capacity. Although the functional role of the vast majority of lncRNAs transcribed in a cell has been subject to much debate (Palazzo and Lee, 2015), the literature shows many examples of their effects on gene expression regulation. The mechanism of action is based on their ability to interact with other molecules, such as DNA, RNA, and proteins. In this way, they can act at different stages of gene expression and in processes ranging from chromatin remodeling to transcriptional, post-transcriptional, and translational regulation (Vance and Ponting, 2014). In addition, a recent analysis of Ruiz-Orera et al. (2014) on ribosome profiling experiments provided important evidence that lncRNAs associated with ribosomes may play an important role in de novo protein evolution by encoding short peptides. A large fraction of tissue-specific lncRNAs is expressed in the brain (Derrien et al., 2012), and many reviews have emphasized their role in neurodevelopment, brain function, and a wide range of neurodevelopmental, neurodegenerative and psychiatric diseases (for instance, see St Laurent and Wahlestedt, 2007; van de Vondervoort et al., 2013; Wu et al., 2013; Barry, 2014; Roberts et al., 2014; Tushir and Akbarian, 2014). An emblematic example is the antisense transcript, Bdnf-AS (Pruunsild et al., 2007). Recently, Modarresi et al. (2012) demonstrated that $B d n f$-AS downregulates $B d n f$ expression through a role in the guidance, introduction, and maintenance of H3K27me3 involving PRC2-mediated repressive chromatin remodeling. Single-stranded oligonucleotides and siRNA-mediated depletion of Bdnf-AS in adult mouse brain resulted in a several-fold increase in Bdnf transcript and protein in the hippocampus and frontal cortex (Modarresi et al., 2012). These results paved the way for considering lncRNA as potential drug targets and to search for new strategies to inhibit BDNFAS function to treat a number of neurological diseases in which $B D N F$ is downregulated. Due to their growing relevance in the regulation of neuronal gene expression, we pondered whether lncRNAs may have a role in the regulatory cascade triggered by BDNF stimulation. In particular, we focused on 
immediate early response to the neurotrophin stimulation to gain insight into the potential involvement of lncRNAs as a master regulator in BDNF-induced neuronal transcriptional changes.

\section{RATIONALE, MATERIALS AND METHODS}

\section{Neuronal Cell Model and Culture Conditions}

We used the popular SHSY-5Y cell line as a neuronal cell model for BDNF stimulation. SHSY-5Y is a neuroblastoma cell line that can be propagated by easy and low-cost methods when in its native undifferentiated status (Kovalevich and Langford, 2013). SHSY-5Y can be differentiated into cells with a more mature and neuron-like phenotype (Kovalevich and Langford, 2013). In particular, for our study, SH-SY5Y cells $\left(\right.$ ATCC $\left.^{\circledR}\right)$ were grown and propagated in Dulbecco's modified Eagle's medium (DMEM, Microtech $\left.{ }^{\circledR}\right)$, supplemented with $2 \mathrm{mM}$ L-glutamine (Lonza BioWhittaker ${ }^{\mathrm{TM}}$ ), and a solution of $1 \%$ penicillin/streptomycin (Lonza BioWhittaker ${ }^{\mathrm{TM}}$ ) and $15 \%$ Fetal Bovine Serum (FBS, Gibco ${ }^{\circledR}$ ). The SHSY-5Y line comprises at least two morphologically and biochemically distinct phenotypes: neuroblastic (N-type) and a low proportion of epithelial-like (S-type; Encinas et al., 2000) phenotypes. For BDNF treatment on a more homogeneous neuronal cell population, we performed an enrichment procedure based on the different substrate adherence between the two cell phenotypes. The obtained N-enriched population of SHSY-5Y was differentiated by decreasing FBS concentration from 15 to $1.5 \%$ and adding $10 \mu \mathrm{M}$ of RA (retinoic acid-RA, SigmaAldrich ${ }^{\circledR}$ ) for 6 days (the medium was refreshed every 2 days). This produced differentiated cells responsive to BDNF, since RA treatment induces the expression of NTRK2 receptor in SH-SY5Y cells (Kaplan et al., 1993; Encinas et al., 2000). After 6 days of differentiation, the medium containing 1.5\% FBS and RA was removed and substituted with a medium without FBS for two groups of cells. One of these groups was treated with $10 \mathrm{ng} / \mathrm{mL}$ of BDNF (PeproTech ${ }^{\circledR}$ ) for a specific time, whereas the second group was not treated and used as a control for the gene expression analysis. We carried out a preliminary investigation to choose the most appropriate time for analyzing the immediate early response to BDNF treatment. We based this analysis on the expression pattern of three immediate early genes downstream of BDNF signaling activation: ARC, NR4A1, and SIK1. The mRNA level of all these genes peaked at $1 \mathrm{~h}$ of BDNF treatment (data not shown). Based on these results, microarray analysis was carried out on RNA extracted after $1 \mathrm{~h}$ BDNFtreatment.

\section{RNA Isolation and Quality}

Total cellular RNA was isolated using an RNeasy ${ }^{\circledR}$ Mini Kit (Qiagen) according to the RNeasy ${ }^{\circledR}$ Mini Handbook (Qiagen). DNA contamination was efficiently removed by on-column
DNAse digestion (Qiagen). The concentration and the purity of the RNA sample were assessed using NanoDrop ${ }^{\circledR} 1000$ (Thermo Scientific). Total RNA quality was assessed by an Agilent 2100 Bioanalyzer (Agilent Technologies).

\section{Microarray Experiment Analysis}

Microarray experiments were performed on biological triplicate samples. Microarray hybridizations were performed by the Transcriptomics and Genomics core facility of the Department of Emergency and Organ Transplants (DETO) - Nephrology Unit - of the University of Bari 'Aldo Moro' Italy ${ }^{1}$. The labeled cRNA was produced using a Low Input Quick Amp Labeling (LIQA) kit (Agilent Technologies) and hybridized for $17 \mathrm{~h}$ at $65^{\circ} \mathrm{C}$ on an Agilent SurePrint G3 $8 \times 60 \mathrm{~K}$ custom lncRNA expression array (Agilent Technologies). This array contains two probes for 22,001 lncRNAs targeting the Gencode v15 human lncRNA annotation, together with one probe for 17,535 randomly chosen protein-coding transcripts. After hybridization, the slide was washed according to Agilent protocols and scanned using a High-Resolution Microarray C Scanner (Agilent Technologies). The image file was processed using Agilent Feature Extraction software (v10.7.3). The microarray grid was correctly placed, and outlier pixels (which were rejected) and inlier pixels were identified. Normalization was performed according to the Quantile method. The differentially expressed probes were selected using a moderated $t$-test with a $p$-value cut-off of 0.05 .

\section{Quantitative RT-PCR}

qPCR validation was performed on independent biological replicates in triplicate. cDNA was synthesized from $1 \mu \mathrm{g}$ of total RNA using an Invitrogen SuperScript III $^{\circledR}$ kit. Real-time PCR was performed using the SYBR green method and an Applied Biosystems 7500 System. The PCR conditions included a denaturation step $\left(95^{\circ} \mathrm{C}\right.$ for $\left.10 \mathrm{~min}\right)$ followed by 40 cycles of

${ }^{1}$ http://www.uniba.it/ricerca/dipartimenti/deto

TABLE 1 | Summary of microarray analysis.

\begin{tabular}{lccc}
\hline Transcript & Number & Differentially expressed & FC $\geq \mathbf{1 . 5}$ \\
\hline IncRNA & 22,001 & 155 & 41 \\
mRNA & 17,535 & 238 & 40
\end{tabular}

TABLE 2 | Top regulated coding and long non-coding transcripts with fold change above 2 .

\begin{tabular}{lcclcc}
\hline Coding & Regulation & FC & IncRNA & Regulation & FC \\
\hline NR4A3 & Up & 9.2 & C6orf176 & Up & 3.8 \\
ARC & Up & 8.3 & Inc-NPAS4-1 & Up & 3.1 \\
RHOB & Up & 4.3 & Inc-WDR1-1 & Up & 2.8 \\
fam46a & Up & 3.6 & IGFBP7-AS1 & Up & 2.1 \\
EGR1 & $U p$ & 3.0 & Inc-ZSCAN10-4 & Up & 2.1 \\
DUSP5 & Up & 3.0 & MIAT-003 & Down & 2.1 \\
KLF10 & $U p$ & 2.3 & MIAT-001 & Down & 2.0 \\
MAP3K14 & Up & 2.0 & Inc-RHOF-1 & Down & 2.0 \\
F3 & $U p$ & 2.0 & & &
\end{tabular}


amplification and quantification $\left(95^{\circ} \mathrm{C}\right.$ for $35 \mathrm{~s}, 60^{\circ} \mathrm{C}$ for $\left.1 \mathrm{~min}\right)$. Relative gene expression levels were normalized to the reference gene hypoxanthine phosphoribosyl transferase 1 (HPRT1) and calculated by the $2^{-\Delta \Delta \mathrm{Ct}}$ method. The sequences of the primers used are reported in Supplementary Table S1.

\section{IncRNA Classification and Functional Analysis}

The LNCipedia database ${ }^{2}$ (Volders et al., 2015) was used for retrieving the transcript ID, gene ID, and alternative gene name of the differentially expressed lncRNAs. Differentially expressed lncRNAs were classified by considering their position relative to adjacent protein-coding genes as reported by Mattick and Rinn (2015). Protein-coding potential of the differentially expressed lncRNAs was assessed by CPAT (Coding-Potential Assessment Tool) software ${ }^{3}$ (Wang et al., 2013). For the functional analysis of the differentially expressed lncRNAs, a list of nearby potentially regulated genes was retrieved using the computational tool GREAT (Genomic Regions Enrichment of Annotations Tool ${ }^{4}$; McLean et al., 2010). Functional enrichment analysis for the predicted target genes and differentially expressed coding genes was performed using the DAVID system (Database for Annotation, Visualization, and Integrated Discovery ${ }^{5}$ ), which uses Gene Ontology (GO) to identify the molecular function represented in the gene profile (Dennis et al., 2003). We obtained a list of potentially regulated miRNAs from $\ln \mathrm{CeDB}^{6}$, a database that provides human IncRNAs (version Gencode 19) that can potentially act as competitive endogenous RNAs (ceRNAs) and interfere with the pathway of miRNAs (Das et al., 2014). These miRNAs were analyzed by miR2Disease ${ }^{7}$ to find miRNAs deregulated in human diseases (Jiang et al., 2009). The potentially regulated miRNAs were also analyzed by miRTarBase ${ }^{8}$ to find their experimentally validated mRNA targets (Chou et al., 2016). The list of the retrieved mRNA was analyzed by the DAVID tool.

\footnotetext{
${ }^{2}$ http://www.lncipedia.org/

${ }^{3}$ http://lilab.research.bcm.edu/cpat/

${ }^{4}$ http://bejerano.stanford.edu/great/public/html/

${ }^{5}$ http://david.abcc.ncifcrf.gov/

${ }^{6} \mathrm{http}: / /$ gyanxet-beta.com/lncedb/

${ }^{7}$ http://www.mir2disease.org/

${ }^{8}$ http://mirtarbase.mbc.nctu.edu.tw/
}

For all the DAVID analyses, the significance of enrichment of each GO term was assessed by a $p$-value of $<0.05$ and ranked by the number of differentially expressed genes (count).

\section{RESULTS AND DISCUSSION}

\section{Summary of Microarray Experiment Results}

Long non-coding RNA expression profiles are summarized in Table 1. We found that 155 lncRNAs and $238 \mathrm{mRNAs}$ were significantly differentially expressed ( $p$-value $<0.05)$. A fold change of $>1.5$ was found in 41 lncRNAs (24 up and 17 down regulated) and 40 mRNAs (31 up and nine down regulated; Table 1, Supplementary Table S2). A panel of both differentially expressed lncRNAs and mRNAs with fold change above 1.5 was validated by qPCR (Supplementary Figure S1). We analyzed the 41 differentially expressed lncRNAs by CPAT software to assess their protein-coding potential. We found that 37 lncRNAs have a coding probability value below the cutoff (0.364), while the remaining $3 \operatorname{lncRNAs}$ have a coding probability value above the cutoff (Supplementary Table S3). Among these three transcripts we found C6orf176, the RNA with the highest fold change in our analysis (Supplementary Tables S2 and S3). The vast majority of the top regulated coding transcripts with fold change above 2 are classical immediate early genes involved in different biological processes in response to various neural stimuli, such as NR4A3, $A R C, E G R 1$, and DUSP5 (Table 2). A number of lncRNAs showed a fold change above 2, including the previously reported C6orf176 and MIAT (also known as Gomafu; Table 2). C6orf176 has been shown to be readily upregulated with a peak at the 2-h time point of treating human ocular ciliary smooth muscle cells with an EP2- and EP4-specific agonist (Reitmair et al., 2012). Notably, there was rapid and pronounced transcriptional upregulation followed by a brisk decline which resembles the kinetics of immediate early response genes (Reitmair et al., 2012). MIAT was recently shown to be acutely regulated in response to neuronal activation in mouse primary cortical neurons (Barry et al., 2014). In particular, this lncRNA is strongly downregulated after $1 \mathrm{~h}$ and $3 \mathrm{~h}$ of $\mathrm{KCl}$ depolarization (Barry et al., 2014). Interestingly, our data are in accordance with that of Barry et al. (2014), since we detected downregulation of MIAT transcript after $1 \mathrm{~h}$ of

TABLE 3 | Differentially expressed IncRNA that have been identified in literature.

\begin{tabular}{|c|c|c|}
\hline Gene symbol & Regulation & Function \\
\hline MALAT1 (Neat2) & Down & $\begin{array}{l}\text { Control of the expression of genes involved in synapse function (Bernard et al., 2010). Down-regulation led to cell arrest in the } \\
\text { G1/S or G2/M phase (Yang et al., 2013). }\end{array}$ \\
\hline MIAT (Gomafu) & Down & $\begin{array}{l}\text { Down-regulated in response to neuronal activation and involved in schizophrenia-associated alternative splicing (Barry et al., } \\
\text { 2014). Decreased in the medial prefrontal complex following fear conditioning and knockdown of promoted stress reactivity and } \\
\text { anxiety-like behavior (Spadaro et al., 2015). Neurogenic commitment and neuronal survival, sustained overexpression of Miat } \\
\text { promoted neuronal death (Aprea et al., 2013). }\end{array}$ \\
\hline HAND2-AS1 (Dein) & Down & $\begin{array}{l}\text { Highly expressed in stage IVS neuroblastoma (Voth et al., 2007). Expression is neuroblastoma is co-regulated together with } \\
\text { HAND2 (Voth et al., 2009). }\end{array}$ \\
\hline C6orf176 & Up & A possible regulatory function in response to cAMP signaling (Reitmair et al., 2012). \\
\hline HOXD-AS1 & Up & $\begin{array}{l}\text { It is induced by RA, could be regulated via PI3K/Akt pathway and controls genes involved in RA signaling, angiogenesis and } \\
\text { inflammation (Yarmishyn et al., 2014). }\end{array}$ \\
\hline
\end{tabular}


A

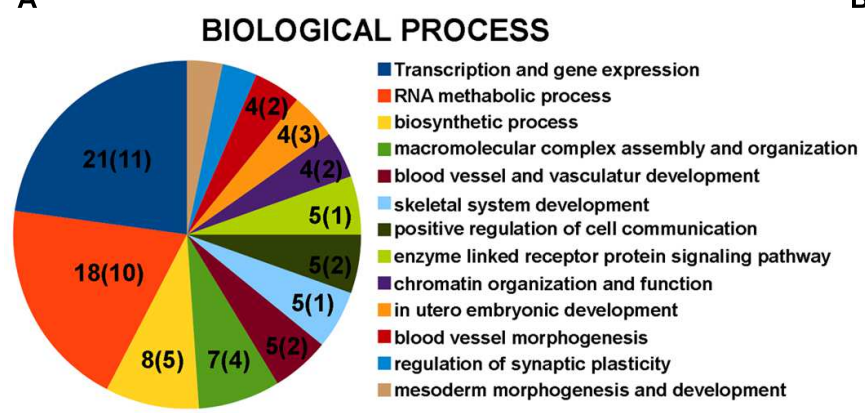

B

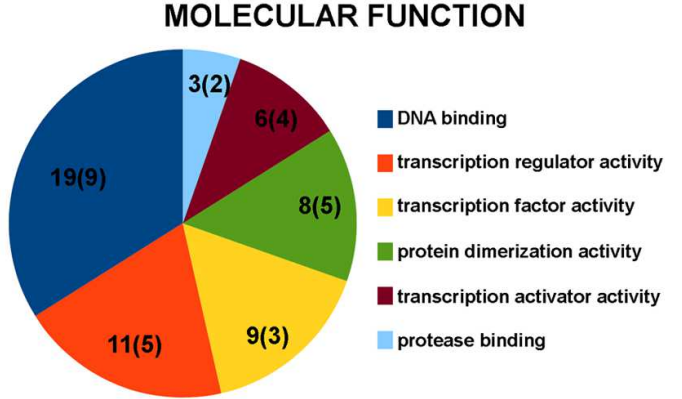

c

CELLULAR COMPONENT

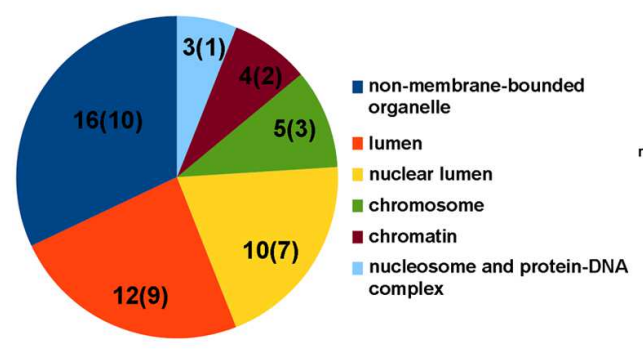

D

TOP 10 BIOLOGICAL PROCESS

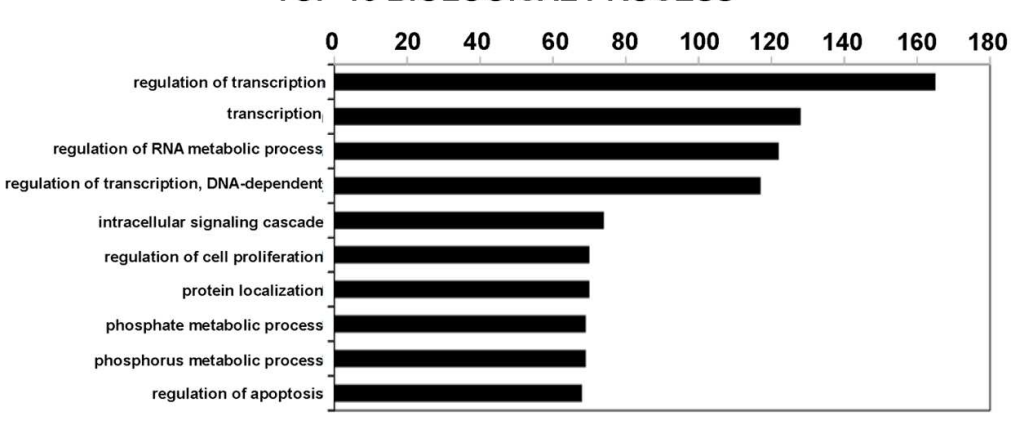

FIGURE 1 | Gene Ontology (GO) enrichment analysis for IncRNAs by DAVID bioinformatics tool. (A) GO analysis of IncRNA-target genes + differentially expressed coding genes according to biological process. (B) GO analysis of IncRNA-target genes + differentially expressed coding genes according to molecular function. (C) GO analysis of IncRNA-target genes + differentially expressed coding genes according to cell component. (D) Top 10 biological processes for coding genes that are target of miRNA potentially regulated by the differentially expressed IncRNAs. Grouped GO terms are reported as following with the ID of the single GO term. Transcription and gene expression: GO:0045449 + GO:0006350 + GO:0006355 + G0:0006357 + GO:0045893 + GO:0045941 + GO:0010628 + GO:0045944; RNA metabolic process: GO:0051252 + GO:0051254 + GO:0045935 + G0:0051173 + GO:0010604; biosynthetic process: G0:0010557 + GO:0031328 + GO:0009891; macromolecular complex assembly and organization: G0:0065003 + G0:0043933 + G0:0034622 + GO:0034621; blood vessel and vasculature development: GO:0001568 + GO:0001944; chromatin organization and function: G0:0006334 + GO:0031497 + GO:0065004 + G0:0034728 + GO:0006323 + GO:0006333; regulation of synaptic plasticity: GO:0048168 + G0:0048167; mesoderm morphogenesis and development: GO:0048332 + GO:0007498. The number on the pie chart indicates the number of differentially expressed coding genes associated to the GO term (or GO group), while the number in brackets indicates the number of genes located near the differentially expressed IncRNAs.

TABLE 4 | Putative miRNA targets on IncRNA and their involvement in neuropsychiatric diseases.

\begin{tabular}{ll}
\hline miRNA symbol & Neuropathology \\
\hline hsa-miR-339-5p & Neurodegeneration \\
hsa-miR-433 & Parkinson's disease \\
hsa-miR-133b & Parkinson's disease \\
hsa-miR-346 & Schizophrenia \\
hsa-miR-328 & Alzheimer's disease \\
hsa-miR-299-3p & Alzheimer's disease \\
hsa-miR-422a & Multiple sclerosis \\
\hline
\end{tabular}

stimulation with BDNF, which is a well known activity-dependent factor.

\section{Classification and Functional Analysis of IncRNA Regulated by BDNF}

The lncRNAs were classified in accordance with the definition discussed in "Materials and Methods" Section. The vast majority of differentially expressed lncRNAs were included in the intergenic and antisense classes (Supplementary Table S2). Five IncRNAs with a fold change above 1.5 were hypothesized to have a role in physiological and pathological processes in neuronal cells by regulating gene expression (Table 3). This supports the hypothesis of an involvement of lncRNA in BDNF-mediated molecular effects. To assess the potential function of the vast majority of the differentially expressed IncRNAs, we examined the function of genes located near the lncRNAs in the genome. The list of these coding genes and the list of differentially expressed coding RNAs found in our microarray survey were used for GO and pathway enrichment analysis with the DAVID tool. GO terms that shared the same genes were grouped together as shown in Figure 1 with the ID of single GO terms. We report the number of genes associated with the GO group in a pie chart with the number of genes located near the lncRNAs in brackets. The most enriched biological processes are related to transcription regulation and RNA metabolic process (Figure 1A). In addition, there are also processes related to chromatin organization and function 
(Figure 1A). The involvement of genomic loci of lncRNA in transcription control was also revealed by GO terms of molecular function (Figure 1B). Regarding cellular component analysis, enriched GO are related to non-membrane-bound organelle, lumen and chromatin structure (Figure 1C).

\section{miRNA Targets on IncRNA}

Long non-coding RNAs can affect gene expression by interfering with the microRNA pathways and acting as competing endogenous RNA. We therefore used the $\operatorname{lnCeDB}$ database to unravel microRNA (miRNA)-lncRNA putative functional interactions by identifying miRNAs with binding sites in differently expressed lncRNAs. Seven of the miRNAs found are associated with neuropathologies reported in the mir2disease database (Table 4). To acquire information on biological processes affected by the putative IncRNA-miRNA interaction, we retrieved a list of experimentally validated mRNA targets of all the previously identified miRNAs and carried out a functional analysis with the DAVID tool. In the top 10 biological processes, the most represented categories are related to the regulation of transcription and RNA metabolic processes (Figure 1D).

\section{CONCLUSION}

The gene expression occurring immediately after neural stimuli plays critical roles in long-lasting neuronal changes. Further efforts are needed to isolate novel IEGs, with the hope of finding "master genes" for neuronal processes and subsequent therapeutic targets for brain diseases. The molecular mechanisms underlying the gene expression regulation in the initial phase of the stimulus-induced molecular cascade comprise the product of coding genes, miRNAs, and very recently, lncRNAs (Aitken et al., 2015). We sought to evaluate the potential role of lncRNAs in early gene expression regulation triggered by the neurotrophin BDNF. In particular, using microarray technology, we found that hundreds of IncRNAs and coding IEGs changed their transcript level after $1 \mathrm{~h}$ of BDNF treatment on neuronal cells. Some of the differentially expressed lncRNAs are already known.

\section{REFERENCES}

Aitken, S., Magi, S., Alhendi, A. M., Itoh, M., Kawaji, H., Lassmann, T., et al. (2015). Transcriptional dynamics reveal critical roles for non-coding RNAs in the immediate-early response. PLoS Comput. Biol. 11:e1004217. doi: 10.1371/journal.pcbi.1004217

Aprea, J., Prenninger, S., Dori, M., Ghosh, T., Monasor, L. S., Wessendorf, E., et al. (2013). Transcriptome sequencing during mouse brain development identifies long non-coding RNAs functionally involved in neurogenic commitment. EMBO J. 32, 3145-3160. doi: 10.1038/emboj.2013.245

Aydemir, O., Deveci, A., and Taneli, F. (2005). The effect of chronic antidepressant treatment on serum brain-derived neurotrophic factor levels in depressed patients: a preliminary study. Prog. Neuropsychopharmacol. Biol. Psychiatry. 29, 261-265. doi: 10.1016/j.pnpbp.2004. 11.009

Barry, G. (2014). Integrating the roles of long and small non-coding RNA in brain function and disease. Mol. Psychiatry 19, 410-416. doi: 10.1038/mp.2013.196
These are strictly associated with neuronal cellular processes and are involved in gene expression regulation. However, the biological functions of a vast majority of lncRNAs identified in this study are not currently understood. We therefore used computational approaches to provide preliminary insights into their potential functionality. The most enriched ontology terms were related to the transcription regulation processes, which highlights the putative role of IncRNAs in orchestrating the immediate response to BDNF. Overall, this study presents an interesting area for further investigations into lncRNAs with essential roles in molecular and cellular processes triggered by neurotrophins.

\section{AUTHOR CONTRIBUTIONS}

Conceived and designed the experiments: AD. Performed the experiments: VA and AD. Analyzed the data: VA and AD. Wrote the paper: $\mathrm{AD}$.

\section{FUNDING}

This work was supported by the MIUR FIRB Grant RBFR12QW4I.

\section{ACKNOWLEDGMENTS}

The authors thank Dr. Matteo Accetturo (matteo.accet turo@uniba.it) of Transcriptomics and Genomics core facility of the Department of Emergency and Organ Transplants (DETO) Nephrology Unit - University of Bari 'Aldo Moro' for execution of microarray hybridizations and analysis.

\section{SUPPLEMENTARY MATERIAL}

The Supplementary Material for this article can be found online at: http://journal.frontiersin.org/article/10.3389/fnmol. 2016.00015

Barry, G., Briggs, J. A., Vanichkina, D. P., Poth, E. M., Beveridge, N. J., Ratnu, V. S., et al. (2014). The long non-coding RNA Gomafu is acutely regulated in response to neuronal activation and involved in schizophrenia-associated alternative splicing. Mol. Psychiatry 19, 486-494. doi: 10.1038/mp.2013.45

Bernard, D., Prasanth, K. V., Tripathi, V., Colasse, S., Nakamura, T., Xuan, Z., et al. (2010). A long nuclear-retained non-coding RNA regulates synaptogenesis by modulating gene expression. EMBO J. 29, 3082-3093. doi: 10.1038/emboj.2010.199

Bibel, M., and Barde, Y. A. (2000). Neurotrophins: key regulators of cell fate and cell shape in the vertebrate nervous system. Genes Dev. 14, 2919-2937. doi: $10.1101 / \mathrm{gad} .841400$

Bramham, C. R., and Messaoudi, E. (2005). BDNF function in adult synaptic plasticity: the synaptic consolidation hypothesis. Prog. Neurobiol. 76, 99-125. doi: 10.1016/j.pneurobio.2005.06.003

Casaccia-Bonnefil, P., Gu, C., and Chao, M. V. (1999). Neurotrophins in cell survival/death decisions. Adv. Exp. Med. Biol. 468, 275-282. doi: 10.1007/9781-4615-4685-6_22 
Chou, C. H., Chang, N. W., Shrestha, S., Hsu, S. D., Lin, Y. L., Lee, W. H., et al. (2016). miRTarBase 2016: updates to the experimentally validated miRNA-target interactions database. Nucleic Acids Res. 44, D239-D247. doi: 10.1093/nar/gkv1258

Cunha, A. B., Frey, B. N., Andreazza, A. C., Goi, J. D., Rosa, A. R., Gonçalves, C. A., et al. (2006). Serum brain-derived neurotrophic factor is decreased in bipolar disorder during depressive and manic episodes. Neurosci. Lett. 398, 215-219. doi: 10.1016/j.neulet.2005.12.085

Das, S., Ghosal, S., Sen, R., and Chakrabarti, J. (2014). lnCeDB: database of human long noncoding RNA acting as competing endogenous RNA. PLoS ONE 9:e98965. doi: 10.1371/journal.pone.0098965

Dennis, G. J., Sherman, B. T., Hosack, D. A., Yang, J., Gao, W., Lane, H. C., et al. (2003). DAVID: database for annotation, visualization, and integrated discovery. Genome Biol. 4:P3. doi: 10.1186/gb-2003-4-5-p3

Derrien, T., Johnson, R., Bussotti, G., Tanzer, A., Djebali, S., Tilgner, H., et al. (2012). The GENCODE v7 catalog of human long noncoding RNAs: analysis of their gene structure, evolution, and expression. Genome Res. 22, 1775-1789. doi: $10.1101 /$ gr.132159.111

Duman, R. S., and Voleti, B. (2012). Signaling pathways underlying the pathophysiology and treatment of depression: novel mechanisms for rapid-acting agents. Trends Neurosci. 35, 47-56. doi: 10.1016/j.tins.2011. 11.004

Encinas, M., Iglesias, M., Liu, Y., Wang, H., Muhaisen, A., Ceña, V., et al. (2000). Sequential treatment of SH-SY5Y cells with retinoic acid and brainderived neurotrophic factor gives rise to fully differentiated, neurotrophic factor-dependent, human neuron-like cells. J. Neurochem. 75, 991-1003. doi: 10.1046/j.1471-4159.2000.0750991.x

Ernfors, P., Kucera, J., Lee, K. F., Loring, J., and Jaenisch, R. (1995). Studies on the physiological role of brain-derived neurotrophic factor and neurotrophin-3 in knockout mice. Int. J. Dev. Biol. 39, 799-807.

Faria, M. C., Gonçalves, G. S., Rocha, N. P., Moraes, E. N., Bicalho, M. A., Gualberto Cintra, M. T., et al. (2014). Increased plasma levels of BDNF and inflammatory markers in Alzheimer's disease. J. Psychiatr. Res. 53, 166-172. doi: 10.1016/j.jpsychires.2014.01.019

Finsterwald, C., Carrard, A., and Martin, J. L. (2013). Role of salt-inducible kinase 1 in the activation of MEF2-dependent transcription by BDNF. PLoS ONE 8:e54545. doi: 10.1371/journal.pone.0054545

Gonul, A. S., Akdeniz, F., Taneli, F., Donat, O., Eker, C., and Vahip, S. (2005). Effect of treatment on serum brain-derived neurotrophic factor levels in depressed patients. Eur. Arch. Psychiatry Clin. Neurosci. 255, 381-386. doi: 10.1007/s00406-005-0578-6

Gottmann, K., Mittmann, T., and Lessmann, V. (2009). BDNF signaling in the formation, maturation and plasticity of glutamatergic and GABAergic synapses. Exp. Brain Res. 199, 203-234. doi: 10.1007/s00221-009-1994-Z

Holsinger, R. M., Schnarr, J., Henry, P., Castelo, V. T., and Fahnestock, M. (2000). Quantitation of BDNF mRNA in human parietal cortex by competitive reverse transcription-polymerase chain reaction: decreased levels in Alzheimer's disease. Brain Res. Mol. Brain Res. 76, 347-354. doi: 10.1016/S0169328X(00)00023-1

Howells, D. W., Porritt, M. J., Wong, J. Y., Batchelor, P. E., Kalnins, R., Hughes, A. J., et al. (2000). Reduced BDNF mRNA expression in the Parkinson's disease substantia nigra. Exp. Neurol. 166, 127-135. doi: 10.1006/exnr.2000.7483

Huang, E. J., and Reichardt, L. F. (2003). Trk receptors: roles in neuronal signal transduction. Annu. Rev. Biochem. 72, 609-642. doi: 10.1146/annurev.biochem.72.121801.161629

Inamura, N., Nawa, H., and Takei, N. (2005). Enhancement of translation elongation in neurons by brain-derived neurotrophic factor: implications for mammalian target of rapamycin signaling. J. Neurochem. 95, 1438-1445. doi: 10.1111/j.1471-4159.2005.03466.x

Jiang, M., Peng, Q., Liu, X., Jin, J., Hou, Z., Zhang, J., et al. (2013). Smallmolecule TrkB receptor agonists improve motor function and extend survival in a mouse model of Huntington's disease. Hum. Mol. Genet. 22, 2462-2470. doi: $10.1093 / \mathrm{hmg} / \mathrm{ddt} 098$

Jiang, Q., Wang, Y., Hao, Y., Juan, L., Teng, M., Zhang, X., et al. (2009). miR2Disease: a manually curated database for microRNA deregulation in human disease. Nucleic Acids Res. 37, D98-D104. doi: 10.1093/nar/gkn714

Kaplan, D. R., Matsumoto, K., Lucarelli, E., and Thiele, C. J. (1993). Induction of TrkB by retinoic acid mediates biologic responsiveness to BDNF and differentiation of human neuroblastoma cells. Neuron 11, 321-331. doi: 10.1016/0896-6273(93)90187-V

Karege, F., Perret, G., Bondolfi, G., Schwald, M., Bertschy, G., and Aubry, J. M. (2002). Decreased serum brain-derived neurotrophic factor levels in major depressed patients. Psychiatry Res. 109, 143-148. doi: 10.1016/S01651781(02)00005-7

Korte, M., Carroll, P., Wolf, E., Brem, G., Thoenen, H., and Bonhoeffer, T. (1995). Hippocampal long-term potentiation is impaired in mice lacking brainderived neurotrophic factor. Proc. Natl. Acad. Sci. U.S.A. 92, 8856-8860. doi: 10.1073/pnas.92.19.8856

Kovalevich, J., and Langford, D. (2013). Considerations for the use of SH-SY5Y neuroblastoma cells in neurobiology. Methods Mol. Biol. 1078, 9-21. doi: 10.1007/978-1-62703-640-5_2

Leal, G., Afonso, P. M., Salazar, I. L., and Duarte, C. B. (2015). Regulation of hippocampal synaptic plasticity by BDNF. Brain Res. 1621, 82-101. doi: 10.1016/j.brainres.2014.10.019

Leal, G., Comprido, D., and Duarte, C. B. (2014). BDNF-induced local protein synthesis and synaptic plasticity. Neuropharmacology 76, 639-656. doi: 10.1016/j.neuropharm.2013.04.005

Linnarsson, S., Bjorklund, A., and Ernfors, P. (1997). Learning deficit in BDNF mutant mice. Eur. J. Neurosci. 9, 2581-2587. doi: 10.1111/j.14609568.1997.tb01687.x

Ma, Y. L., Wang, H. L., Wu, H. C., Wei, C. L., and Lee, E. H. (1998). Brain-derived neurotrophic factor antisense oligonucleotide impairs memory retention and inhibits long-term potentiation in rats. Neuroscience 82, 957-967. doi: 10.1016/S0306-4522(97)00325-4

Mattick, J. S., and Rinn, J. L. (2015). Discovery and annotation of long noncoding RNAs. Nat. Struct. Mol. Biol. 22, 5-7. doi: 10.1038/nsmb.2942

McLean, C. Y., Bristor, D., Hiller, M., Clarke, S. L., Schaar, B. T., Lowe, C. B., et al. (2010). GREAT improves functional interpretation of cis-regulatory regions. Nat. Biotechnol. 28, 495-501. doi: 10.1038/nbt.1630

Michalski, B., and Fahnestock, M. (2003). Pro-brain-derived neurotrophic factor is decreased in parietal cortex in Alzheimer's disease. Brain Res. Mol. Brain Res. 111, 148-154. doi: 10.1016/S0169-328X(03)00003-2

Minichiello, L. (2009). TrkB signalling pathways in LTP and learning. Nat. Rev. Neurosci. 10, 850-860. doi: 10.1038/nrn2738

Mizui, T., Tanima, Y., Komatsu, H., Kumanogoh, H., and Kojima, M. (2014). The biological actions and mechanisms of brain-derived neurotrophic factor in healthy and disordered brains. Neurosci. Med. 5, 183-195. doi: 10.4236/nm.2014.54021

Modarresi, F., Faghihi, M. A., Lopez-Toledano, M. A., Fatemi, R. P., Magistri, M., Brothers, S. P., et al. (2012). Inhibition of natural antisense transcripts in vivo results in gene-specific transcriptional upregulation. Nat. Biotechnol. 30, 453459. doi: 10.1038/nbt. 2158

Mu, J. S., Li, W. P., Yao, Z. B., and Zhou, X. F. (1999). Deprivation of endogenous brain-derived neurotrophic factor results in impairment of spatial learning and memory in adult rats. Brain Res. 835, 259-265. doi: 10.1016/S00068993(99)01592-9

Nagahara, A. H., and Tuszynski, M. H. (2011). Potential therapeutic uses of BDNF in neurological and psychiatric disorders. Nat. Rev. Drug Discov. 10, 209-219. doi: $10.1038 / \mathrm{nrd} 3366$

Palazzo, A. F., and Lee, E. S. (2015). Non-coding RNA: what is functional and what is junk? Front. Genet. 6:2. doi: 10.3389/fgene.2015.00002

Park, H., and Poo, M. M. (2013). Neurotrophin regulation of neural circuit development and function. Nat. Rev. Neurosci. 14, 7-23. doi: 10.1038/nrn3379

Patterson, S. L., Abel, T., Deuel, T. A. S., Martin, K. C., Rose, J. C., and Kandel, E. R. (1996). Recombinant BDNF rescues deficits in basal synaptic transmission and hippocampal LTP in BDNF knockout mice. Neuron 16, 1137-1145. doi: 10.1016/S0896-6273(00)80140-3

Peng, S., Wuu, J., Mufson, E. J., and Fahnestock, M. (2005). Precursor form of brain-derived neurotrophic factor and mature brain-derived neurotrophic factor are decreased in the pre-clinical stages of Alzheimer's disease. J. Neurochem. 93, 1412-1421. doi: 10.1111/j.1471-4159.2005. 03135.x

Pruunsild, P., Kazantseva, A., Aid, T., Palm, K., and Timmusk, T. (2007). Dissecting the human BDNF locus: bidirectional transcription, complex splicing, and multiple promoters. Genomics 90, 397-406. doi: 10.1016/j.ygeno.2007. 05.004 
Rao, V. R., Pintchovski, S. A., Chin, J., Peebles, C. L., Mitra, S., and Finkbeiner, S. (2006). AMPA receptors regulate transcription of the plasticity-related immediate-early gene Arc. Nat. Neurosci. 9, 887-895. doi: 10.1038/nn1708

Reitmair, A., Sachs, G., Im, W. B., and Wheeler, L. (2012). C6orf176: a novel possible regulator of cAMP-mediated gene expression. Physiol. Genomics 44, 152-161. doi: 10.1152/physiolgenomics.00089.2011

Roberts, T. C., Morris, K. V., and Wood, M. J. (2014). The role of long non-coding RNAs in neurodevelopment, brain function and neurological disease. Philos. Trans. R. Soc. Lond. B Biol. Sci. 369:20130507. doi: 10.1098/rstb.2013.0507

Ruiz-Orera, J., Messeguer, X., Subirana, J. A., and Alba, M. M. (2014). Long non-coding RNAs as a source of new peptides. Elife 3:e03523. doi: 10.7554/eLife.03523

Spadaro, P. A., Flavell, C. R., Widagdo, J., Ratnu, V. S., Troup, M., Ragan, C., et al. (2015). Long noncoding RNA-directed epigenetic regulation of gene expression is associated with anxiety-like behavior in mice. Biol. Psychiatry 78, 848-859. doi: 10.1016/j.biopsych.2015.02.004

St Laurent, G. III, and Wahlestedt, C. (2007). Noncoding RNAs: couplers of analog and digital information in nervous system function? Trends Neurosci. 30, 612-621. doi: 10.1016/j.tins.2007.10.002

Suliman, S., Hemmings, S. M., and Seedat, S. (2013). Brain-derived neurotrophic factor (BDNF) protein levels in anxiety disorders: systematic review and metaregression analysis. Front. Integr. Neurosci. 7:55. doi: 10.3389/fnint.2013.00055

Takei, N., Inamura, N., Kawamura, M., Namba, H., Hara, K., Yonezawa, K., et al. (2004). Brain-derived neurotrophic factor induces mammalian target of rapamycin-dependent local activation of translation machinery and protein synthesis in neuronal dendrites. J. Neurosci. 24, 9760-9769. doi: 10.1523/JNEUROSCI.1427-04.2004

Takei, N., Kawamura, M., Hara, K., Yonezawa, K., and Nawa, H. (2001). Brain-derived neurotrophic factor enhances neuronal translation by activating multiple initiation processes: comparison with the effects of insulin. J. Biol. Chem. 276, 42818-42825. doi: 10.1074/jbc.M103237200

Tushir, J. S., and Akbarian, S. (2014). Chromatin-bound RNA and the neurobiology of psychiatric disease. Neuroscience 264, 131-141. doi: 10.1016/j.neuroscience.2013.06.051

van de Vondervoort, I. I., Gordebeke, P. M., Khoshab, N., Tiesinga, P. H., Buitelaar, J. K., Kozicz, T., et al. (2013). Long non-coding RNAs in neurodevelopmental disorders. Front. Mol. Neurosci. 6:53. doi: 10.3389/fnmol.2013.00053

van der Kolk, N. M., Speelman, A. D., van Nimwegen, M., Kessels, R. P., IntHout, J., Hakobjan, M., et al. (2015). BDNF polymorphism associates with decline in set shifting in Parkinson's disease. Neurobiol. Aging 36, 1605.e1-1605.e6. doi: 10.1016/j.neurobiolaging.2014.08.023

Vance, K. W., and Ponting, C. P. (2014). Transcriptional regulatory functions of nuclear long noncoding RNAs. Trends Genet. 30, 348-355. doi: 10.1016/j.tig.2014.06.001

Vo, N., Klein, M. E., Varlamova, O., Keller, D. M., Yamamoto, T., Goodman, R. H., et al. (2005). A cAMP-response element binding protein-induced microRNA regulates neuronal morphogenesis. Proc. Natl. Acad. Sci. U.S.A. 102, 1642616431. doi: 10.1073/pnas.0508448102

Volders, P. J., Verheggen, K., Menschaert, G., Vandepoele, K., Martens, L., Vandesompele, J., et al. (2015). An update on LNCipedia: a database for annotated human IncRNA sequences. Nucleic Acids Res. 43, 4363-4364. doi: $10.1093 / \mathrm{nar} / \mathrm{gkv} 295$

Voth, H., Oberthuer, A., Simon, T., Kahlert, Y., Berthold, F., and Fischer, M. (2007). Identification of DEIN, a novel gene with high expression levels in stage IVS neuroblastoma. Mol. Cancer Res. 5, 1276-1284. doi: 10.1158/1541-7786.MCR06-0258

Voth, H., Oberthuer, A., Simon, T., Kahlert, Y., Berthold, F., and Fischer, M. (2009). Co-regulated expression of HAND2 and DEIN by a bidirectional promoter with asymmetrical activity in neuroblastoma. BMC Mol. Biol. 10:28. doi: 10.1186/1471-2199-10-28

Wang, L., Park, H. J., Dasari, S., Wang, S., Kocher, J. P., and Li, W. (2013). CPAT: coding-potential assessment tool using an alignment-free logistic regression model. Nucleic Acids Res. 41, e74. doi: 10.1093/nar/gkt006

Weissmiller, A. M., and Wu, C. (2012). Current advances in using neurotrophic factors to treat neurodegenerative disorders. Transl. Neurodegener. 1:14. doi: 10.1186/2047-9158-1-14

Wu, P., Zuo, X., Deng, H., Liu, X., Liu, L., and Ji, A. (2013). Roles of long noncoding RNAs in brain development, functional diversification and neurodegenerative diseases. Brain Res. Bull. 97, 69-80. doi: 10.1016/j.brainresbull.2013.06.001

Xu, B., Gottschalk, W., Chow, A., Wilson, R. I., Schnell, E., Zang, K., et al. (2000). The role of brain-derived neurotrophic factor receptors in the mature hippocampus: modulation of long-term potentiation through a presynaptic mechanism involving trkB. J. Neurosci. 20, 6888-6897.

Yang, F., Yi, F., Han, X., Du, Q., and Liang, Z. (2013). MALAT-1 interacts with hnRNP C in cell cycle regulation. FEBS Lett. 587, 3175-3181. doi: 10.1016/j.febslet.2013.07.048

Yarmishyn, A. A., Batagov, A. O., Tan, J. Z., Sundaram, G. M., Sampath, P., Kuznetsov, V. A., et al. (2014). HOXD-AS1 is a novel lncRNA encoded in HOXD cluster and a marker of neuroblastoma progression revealed via integrative analysis of noncoding transcriptome. BMC Genomics 15:S7. doi: 10.1186/1471-2164-15-S9-S7

Ying, S. W., Futter, M., Rosenblum, K., Webber, M. J., Hunt, S. P., Bliss, T. V., et al. (2002). Brain-derived neurotrophic factor induces longterm potentiation in intact adult hippocampus: requirement for ERK activation coupled to CREB and up-regulation of Arc synthesis. J. Neurosci. 22, 1532-1540.

Zagrebelsky, M., and Korte, M. (2014). Form follows function: BDNF and its involvement in sculpting the function and structure of synapses. Neuropharmacology 76, 628-638. doi: 10.1016/j.neuropharm.2013. 05.029

Zheng, F., Luo, Y., and Wang, H. (2009). Regulation of brain-derived neurotrophic factor-mediated transcription of the immediate early gene Arc by intracellular calcium and calmodulin. J. Neurosci. Res. 87, 380-392. doi: 10.1002/jnr. 21863

Zuccato, C., Marullo, M., Conforti, P., MacDonald, M. E., Tartari, M., and Cattaneo, E. (2008). Systematic assessment of BDNF and its receptor levels in human cortices affected by Huntington's disease. Brain Pathol. 18, 225-238. doi: 10.1111/j.1750-3639.2007.00111.x

Conflict of Interest Statement: The authors declare that the research was conducted in the absence of any commercial or financial relationships that could be construed as a potential conflict of interest.

Copyright (c) 2016 Aliperti and Donizetti. This is an open-access article distributed under the terms of the Creative Commons Attribution License (CC BY). The use, distribution or reproduction in other forums is permitted, provided the original author(s) or licensor are credited and that the original publication in this journal is cited, in accordance with accepted academic practice. No use, distribution or reproduction is permitted which does not comply with these terms. 